"El crimen de Brian". La legitimación de la baja en la edad de imputabilidad en el discurso del diario Clarín

Rocío Baquero

Question, Vol. 1, N. 56, e004, octubre-diciembre 2017. ISSN 1669-6581

http://perio.unlp.edu.ar/ojs/index.php/question/article/view/4431

FPyCS | Universidad Nacional de La Plata

La Plata | Buenos Aires | Argentina

Recibido: 20-10-2017 Aceptado: 17-11-2017

Cita sugerida: Baquero, R. (2017). "El crimen de Brian". La legitimación de la baja en la edad de imputabilidad en el discurso del diario Clarín. Question, 1(56), e004. doi: https://doi.org/10.24215/16696581e004

\title{
“El crimen de Brian”. La legitimación de la baja en la edad de imputabilidad en el discurso del diario Clarín
}

\section{"Brian's crime." The legitimization of the decline in the age of imputability in the speech of the newspaper Clarín}

\section{Rocío Baquero}

Instituto de Investigaciones Gino Germani; Facultad de Ciencias Sociales; Universidad de Buenos Aires (Argentina) rociobaquero@gmail.com

\section{Resumen}

El trabajo analiza la construcción discursiva de los jóvenes en conflicto con la ley penal en la cobertura del diario Clarín en el caso "el crimen de Brian", que reactualizó el debate público sobre la baja en la edad de imputabilidad. El objetivo es relevar e identificar las modalidades enunciativas y estrategias retóricas privilegiadas mediante las que se elaboran representaciones fundantes de legitimidad acerca de la niñez y la adolescencia en relación con la violencia y el delito. El corpus de trabajo está constituido por noticias policiales publicadas 
por el diario en su edición digital durante fines de diciembre de 2016, enero y febrero de 2017. El estudio de la construcción del caso como acontecimiento policial -por tanto también políticopermite identificar de qué manera la baja de imputabilidad como tópico del discurso aparece legitimado.

Palabras clave: jóvenes; delito; discursos; medios.

\section{Abstract}

The paper analyzes the discursive construction of young people in conflict with the criminal law in the coverage of the newspaper Clarín in the case "Brian's crime" that reactualized the public debate about the decline in the age of imputability. The objective is to relieve and identify the enunciative modalities and privileged rhetorical strategies through which fundaments represent legitimacy about childhood and adolescence in relation to violence and crime. The corpus of work is constituted by police news published by the newspaper in its digital edition during the end of December 2016, January and February 2017. The study of the construction of the case as a police event -therefore also political- allows identifying what Thus the fall of imputability as a topic of discourse appears legitimized.

Keywords: young people; crime; speeches; media.

El discurso se entiende desde una perspectiva de los discursos sociales, como hecho social e histórico (Angenot, 2010) y desde una concepción dialógica de los enunciados en la cadena de la comunicación discursiva (Bajtín, 1979). Atendiendo a la discursividad como proceso continuo de producción, circulación y reconocimiento (Verón, 1985) procuramos focalizar en las gramáticas de producción y describir las huellas de las condiciones productivas del discurso. La propuesta es rastrear las marcas de subjetividad en el lenguaje: apelativos, modalidades y subjetivemas; los recursos retóricos y las formas de polifonía en tanto propiedades significantes que remiten a las condiciones de producción.

La relevancia del diario Clarín está dada por ser uno de los principales medios de la prensa gráfica de referencia en la Argentina. Los medios de comunicación se erigen en la actualidad como actores que ejercen influencia en la implementación de políticas públicas, territorio de debates que disputan poder y sentido en el espacio público, donde se deciden los modos de explicar la sociedad y construir el sentido de la realidad (Arancibia, 2009). Esto implica considerar la producción de consenso y legitimidad como uno de los aspectos claves de los 
efectos ideológicos de los medios (Hall, 1981; Gramsci, 1949 y 1984). La cuestión de los jóvenes vinculados al delito se constituye en objeto de discurso (Charaudeau y Maingueneau, 2005) y ancla en preconstruidos culturales propios del dominio al cual convoca el objeto, que da lugar a cadenas de expectativas que pueden afianzarse o modificarse (Arnoux, 2006). Esto supone atender a la interdiscursividad como lugar en el que se constituyen los objetos del discurso y las articulaciones entre estos (Courtine, 1981).

En el campo de la comunicación pública, una multiplicidad de discursos legales, políticos, institucionales y mediáticos versan, con interferencias, sobre la "problemática" de los jóvenes en relación con el delito, constituyéndola en una arena de lucha simbólica en donde se disputan diversos sentidos (Voloshinov, 1929) que exigen ser interpretados en el marco de las nociones más amplias de ciudadanía y derechos humanos.

En las primeras décadas del siglo XX diversos discursos y políticas sociales condujeron a la creación de dispositivos legales que construyeron el "sujeto menor" (Zapiola, 2008) en lo que fue un proceso de minorización de un amplio sector de la niñez, víctima de operaciones de estigmatización y judicialización (Daroqui y Guemureman, 1999 y 2001). La Ley de Patronato también Ilamada Ley Agote por quien la propulsara en 1919, inició en Sudamérica el sistema de patronato del Estado sobre niños y jóvenes de menos de 18 años considerados "material o moralmente abandonados o en peligro moral". Así los "menores" irrumpieron en el campo político- legislativo y social como el nuevo "problema" de Estado, y los sentidos dominantes de la época permanecen todavía vigentes en los debates parlamentarios más recientes (Contursi, Brescia y Costanzo, 2010; Brescia, 2011).

Desde la Convención de los Derechos del Niño (1989) el cambio de paradigma en la concepción del menor como objeto de tutelaje a otra de la infancia y adolescencia como sujeto pleno de derechos manifiesta tensiones y contradicciones diversas. La sanción en 2005 de la Ley de Protección Integral de los Derechos de Niñas, Niños y Adolescentes (26061), que concibe a este sector como sujetos plenos de derechos convive con el Régimen Penal de Minoridad establecido por decreto en la última dictadura militar. Desde que la Convención de los Derechos del Niño fue incorporada a la Constitución Nacional en 1994, la adecuación normativa de las leyes a sus prerrogativas se tornó imperante; desde entonces proliferaron proyectos de ley presentados en el Congreso nacional centrados tanto en la protección y promoción de derechos como en la de regulación y responsabilización penal (1). Los discursos sociales cargados de prejuicios y estereotipos negativos sobre niños y adolescentes en relación con el delito obturan la consideración de estos como sujetos plenos de derechos; arraigados en prácticas y patrones institucionales se reproducen en los medios de comunicación diariamente.

La Convención sobre los Derechos del Niño, el Fondo de Naciones Unidas para la Infancia (UNICEF), entre otros organismos, y la Ley de Protección Integral (26061) establecen un marco 
normativo nacional e internacional con elevados estándares de protección de derechos de los niños, niñas y adolescentes en relación a cómo deben ser tratados por los medios masivos de comunicación. Como señalan, entre otros, informes del Observatorio de Jóvenes Comunicación y Medios de la Universidad Nacional de La Plata (2012) los temas de violencia en relación con niños y adolescentes carecen de una adecuada contextualización, evidencian el uso de términos peyorativos y aluden escasamente a la legislación. Asimismo, cuando se reedita la discusión en torno a la baja de imputabilidad aparece con mayor vehemencia el entrecruzamiento entre juventud, pobreza y delito, en el que la punición se exhibe como la principal moneda de cambio para los sectores de bajos recursos.

\section{El caso del crimen de Brian en el diario Clarín. La noticia policial}

El 24 de diciembre de 2016 un joven llamado Brian Aguinaco fue herido durante un asalto en el barrio de Flores y murió dos días después. La gravedad operó como criterio de noticiabilidad y la producción de información en serie, que incluyó en forma reiterada la vinculación de un adolescente presuntamente involucrado en el homicidio, configuró el acontecimiento en un caso paradigmático sobre el que se respaldaron reclamos sociales y políticos por la baja en la edad de imputabilidad de los 16 a los 14 años. Como sostiene Ford (1999), en tanto algo que sucede a nivel individual o microsocial y que es expuesto mediante una estructura discursiva básicamente narrativa, la narración de casos pone en juego diversos sistemas de generalización. El caso ocupa el lugar de la discusión pública, lo que supone la simplificación, personalización y narrativización que oculta o elude problemáticas estructurales y está conectado con discursos didácticos y moralizantes (Ford, 1994; 1999).

Como respuesta a los sucesos mediatizados (la muerte del joven, la toma de una comisaría y otras manifestaciones públicas) el gobierno nacional se mostró decidido a implementar la baja en la edad de imputabilidad, lo que provocó reacciones opositoras desde sectores políticos y sociales diversos suscitando un intenso debate público sobre la reforma del sistema penal juvenil que se diluyó al cabo de dos meses. A pesar de que el gobierno no consiguió consenso, siguió adelante en la elaboración de un proyecto para bajar la edad en delitos graves como homicidios y violaciones que aún permanece en discusión en el Poder Ejecutivo. La agenda mediática presionó sobre la agenda política y el caso policial se constituyó en un acontecimiento político.

En la construcción del caso que realiza Clarín en la noticia policial, podemos identificar tres núcleos centrales del discurso. En primer lugar, la construcción de un clima social convulsionado desde la noticia del asalto hasta unos días después de la muerte del joven; en segundo lugar, la representación de los jóvenes en relación con el delito; y en tercer término, la 
configuración de las víctimas y victimarios y consecuentemente del rol del Estado. El análisis focaliza en esas tres instancias para dar cuenta de las modalidades privilegiadas y los sentidos explícitos e implícitos puestos en circulación.

\section{La crónica de la indignación vecinal}

El acontecimiento se hace noticiable y se jerarquiza en la crónica policial adjetivado como un asalto trágico y violento episodio. Las primeras crónicas señalan a los agentes del crimen como "motochorros".

Fue en Flores, horas antes de Nochebuena. Motochorros asaltaron a una joven y un hombre de 69 años los cruzó con su coche. Los tiros de los ladrones hirieron al adolescente, que anoche luchaba por su vida. Vecinos protestaron frente a la comisaría (...) El trágico asalto conmocionó a los vecinos de Flores, en la previa de la Nochebuena. "Los chicos quedaron con mucho miedo. Mi hija no quiso salir a la calle para festejar después de la medianoche. Prefirió quedarse en el patio", contó Celeste, una de las vecinas que se reunió esta tarde, a partir de las 18, en la esquina de Asamblea y Rivera Indarte. Una hora más tarde se movilizaron hacia la comisaría $38^{\circ}$, en Bonorino y Alberdi. Allí se vivieron algunos momentos de tensión cuando, tras la promesa de un encuentro con jefes policiales, varias personas intentaron ingresar por la fuerza a la seccional. Luego esperaron la reunión en la puerta, bajo el grito de "que se vayan todos".

El objetivo de la marcha vecinal fue, una vez más, reclamar seguridad. Los testimonios coinciden en que nadie se salva de los robos. Denuncian que grandes y chicos son asaltados a cualquier hora, y que las motos en la que se movilizan los ladrones son "siempre son las mismas".

La seguridad había centralizado la agenda del barrio tras el crimen de Pascual Mollo, cometido a siete cuadras del lugar en el que balearon a Brian (Clarín, 26 de diciembre de 2016).

Los tiempos verbales narrativos (2) estructuran el relato; el uso del perfecto simple (le dispararon y balearon a su nieto), el imperfecto (luchaba por su vida), se utilizan tanto para describir el hecho delictivo como las posteriores acciones de los vecinos de la víctima (se movilizaron/intentaron ingresar/esperaron en la puerta) y sitúan el episodio en una cronología de casos más amplia (La seguridad había centralizado la agenda del barrio). El uso de estos tiempos verbales es una marca predominante de la crónica policial que, mediante el borramiento de las huellas de enunciación, produce el efecto de que los hechos hablan por sí solos. Alternativamente, el uso del tiempo presente (los testimonios coinciden/denuncian) y de verbos marcados subjetivamente (conmocionó a los vecinos) funcionan como comentario que argumenta sobre la omnipresencia del delito (una vez más reclamar seguridad/que nadie se salva de los robos/a cualquier hora.) Las marcas de localización espacial y temporal refuerzan 
lo narrado (tras el crimen Pascual Mollo/a siete cuadras del lugar en el que balearon a Brian) y configuran el barrio de Flores como territorio amenazante.

Luego de que se conociera la muerte de Brian los acontecimientos surgidos a partir de la toma de la comisaría 38 de Flores y la represión policial allí ocurrida son descriptas en las noticias como "incidentes" "momentos de tensión" y "empujones con policías que resistían con sus escudos".

Título: Incidentes en la comisaría de Flores tras el crimen de un adolescente

Cuerpo de la nota: Cerca de las 21 se vivieron los momentos de mayor tensión. El grupo más violento, entre los que había varios hombres con camisetas de fútbol, protagonizaron empujones con policías que resistían con sus escudos. También hubo insultos al jefe de Gobierno Porteño, Horacio Rodríguez Larreta, y a la ministra de Seguridad de la Nación, Patricia Bullrich, a quienes le reclamaban la presencia en el lugar (...) varios de los manifestantes se mostraron en desacuerdo con la violencia: "Venimos pidiendo seguridad y así no la vamos a conseguir", le decían a Clarín. ¿Cuál era el principal reclamo? Más presencia policial, operativos de prevención y controles a las motos. "El pueblo se está manifestando. ¿Qué esperan? ¿Otra muerte?”, se quejaba uno de los vecinos (Clarín, 26 de diciembre de 2016b. Las negritas son siempre del diario).

La represión se niega por la pasividad otorgada al agente policial y se relativiza en la oposición el grupo más violento/manifestantes en desacuerdo con la violencia; la descripción permite inferir que la violencia es ejercida por miembros de barras de fútbol y rechazada por los vecinos que piden seguridad. La asociación entre violencia y vecinos es poco probable en estas crónicas dado el lugar que ocupa el vecino como categoría en el discurso de Clarín específicamente en la tematización de la inseguridad, como se podrá ver más adelante.

La bronca de la gente de Flores, que denuncia que diariamente es víctima de los robos, llegó al pico máximo tras los dos crímenes de este mes: el sábado 10, Pascual José Mollo (69) salía a despedir a los invitados del cumpleaños de su hija cuando fue asesinado por ladrones que intentaron meterse en su casa. El sábado pasado, Enrique Aguinaco (69) volvía de la peluquería con su nieto Brian (14) en su coche. Un motochorro que había asaltado a una vecina disparó dos tiros contra el auto. Un balazo le dio al adolescente. Murió, luego de agonizar durante tres días (Idem).

Los adjetivos y adverbios subjetivos (Kerbrat-Obrecchioni, 1981) (3) bronca/diariamente que remiten a un juicio sobre el sujeto del enunciado "la gente", víctima por definición, sumada a la enumeración de crímenes describen la indignación vecinal frente al delito. El discurso argumenta apelando a citas de autoridad que producen un efecto de legitimidad sobre los testimonios de los vecinos y las evaluaciones de los hechos: 
La preocupación por los hechos violentos no es nueva y se refleja en los números oficiales. El último informe de la Unidad de Derechos Humanos, Género, Trata de personas y Narcotráfico del Consejo de la Magistratura de la Nación posicionó a Flores como el barrio con más homicidios de la Capital Federal, con 40 de los 175 crímenes registrados durante 2015. La mayoría de los casos ocurrieron en la villa 1-1114, donde hubo 28 homicidios (Clarín, 26 de diciembre de 2016).

Los números se reflejaron ayer en las historias de los manifestantes. Mario Zumbo fue a la marcha, pero se quedó del lado más pacífico. Vivía al lado de la casa de Brian y, desde que supo de su muerte, no dejó de pensar en sus hijos de 16 y 13 años (Clarín, 26 de diciembre de 2016b).

Los datos estadísticos ligados al dramatismo del relato de los vecinos construyen el barrio de Flores como territorio del máximo peligro -el barrio con más homicidios de la Capital Federal- y circunscriben el epicentro del delito en la villa 1-11-14. En la serie de notas que despliega el caso desde el inicio, la mayoría de estas aparecen agrupadas bajo los cintillos "inseguridad" o "inseguridad en Capital"; lo que en este momento del discurso refuerza la asociación de etiquetamiento entre el delito y las demandas de mayor seguridad ciudadana; más adelante se restringirá al delito cometido por menores de edad.

\section{La construcción del "menor delincuente"}

La construcción narrativa pone en escena un encadenamiento discursivo de tipo entimemático, es decir, aquel que está compuesto de enunciados lacunarios que ponen en relación lo particular y lo universal y que supone una coherencia relacional del universo del discurso (Angenot, 1982). En los enunciados de testimonios de los familiares de la víctima, especialmente, aparece como una implicación lógica que los menores son conscientes de sus actos y, por lo tanto, adultos, y tienen que ser condenados como tales. La edad no funciona como atenuante sino como aquello que habilita a seguir cometiendo crímenes.

"Todos son concientes con 14, 15 años, de las cosas que hacen. Sabés que si agarrás un arma y apretás el gatillo podés matar a alguien. Sabés que si agarrás un cuchillo y se lo clavás a alguien podés matar. $Y$ si son concientes y se mandaron un problema grande, que sean condenados como tiene que ser. No porque tenga 15 años es un nene, una criatura" (Clarín, 8 de enero de 2017).

Otro de los que habló fue un tío de Brian, Maxi, y al igual que Eduardo se mostró conforme con la investigación pero también bregó: "Un menor no puede matar y salir como si nada, porque vuelve a matar" (Clarín, 2 de enero de 2017).

Los enunciados referidos son marca predominante en la reconstrucción de los hechos que hace la crónica policial, los testimonios de los vecinos son retomados como fuente de fidelidad 
absoluta; "relatan" "cuentan" a Clarín "la realidad que viven" y su palabra ocupa en el discurso un lugar de autoridad.

Como señala Tufró, los vecinos ejercen en el discurso de Clarín un privilegio epistémico y deóntico, este último "coloca al colectivo como detentador de una voluntad única y posiciona a los vecinos como aquellos cuya opinión debe ser decisiva en cuestiones de políticas públicas: hay que escuchar a los vecinos, hay que hacer lo que piden o exigen los vecinos" (2017: 130).

En el fragmento que sigue, el enunciador periodístico les asigna a los vecinos un rol de organización y vigilancia sobre el avance del caso y las reformas legislativas en relación a la baja de edad de imputabilidad:

Pero no sólo la inseguridad preocupa a los vecinos del barrio Fonavi. También están atentos a la investigación del crimen de Brian y a lo que puede pasar con la causa. Están inquietos ante la posibilidad de que liberen al chico de 15 años detenido por el homicidio. Por eso están organizando más marchas (la próxima sería de noche y con velas) y pidiendo asesoramiento para sugerirle a los legisladores la baja en la edad de imputabilidad, un debate que se instaló en estos días luego de que se conociera la idea del Gobierno de una reforma (Clarín, 5 de enero de 2017).

La organización vecinal para sugerir la baja en la edad de imputabilidad tiene su correlato en enunciados tipificantes (Bruxelles y De Chanay, 1998) en los que los vecinos caracterizan a los jóvenes vinculados al delito como sujetos inescrupulosos, incapaces de modificar su conducta al punto que son sus propios padres los que piden que acaben con sus vidas porque no los pueden controlar.

"Acá llegué a ver a pibes robando el Día del Niño: le quitaban los juguetes que habían comprado los papás para sus hijos", resume. (...) Jorge recuerda que en rol de Estado que a veces desarrollan los vecinos también les tocó ir a las casas de estos ladrones, para hablar con sus padres. "Casi todos nos decían lo mismo: 'por mí, matalo, no lo puedo controlar. Acá también nos robó y nos pega. Ya no sabemos qué hacer con él' (Clarín, 2 de enero de 2017).

La falta de escrúpulos y ausencia de códigos de la jerga delictiva socialmente compartidos (roban hasta [a] sus propios vecinos) da dimensión de la peligrosidad, que se asocia directamente a la condición de menor:

Título: La banda que mató a Brian les roba hasta sus propios vecinos en la villa 1-11-14

Bajada y cuerpo de la nota: Son cerca de 30 ladrones. Atacan a las víctimas cuando entran y salen del barrio para ir a trabajar. Dos fueron detenidos por el crimen del adolescente de 14 años en Flores.

Los señalados tienen las particularidades de los detenidos por el crimen de Brian: son jóvenes (muchos son menores), se mueven en motos, y serían, en promedio, unos treinta. Desde el homicidio del 
adolescente -por el que cayó un chico de 15 años y un joven de 26, ambos de la 1-11-14- hay una banda del barrio que dejó de verse (Clarín, 2 de enero de 2017).

La suma de inferencias sobre los jóvenes y su relación con el delito en esta misma noticia permite identificar en el siguiente fragmento la constitución de un topos específico gradual: "cuanto más jóvenes, más peligrosos".

Los ladrones grandes del barrio también les tienen "respeto" a los que hoy son los "dueños del lugar". No solo dejaron de comprometerse en la conducta de los más jóvenes. Ni bien pudieron, siempre a partir de sus robos, compraron casas en otros barrios (de clase media y hasta en countries) y se mudaron. "Cada tanto vuelven para saludar a sus familias en autos carísimos", aclara Jorge. Y agrega: "Pero se van rápido, por estos pibes. Es que ellos andan enfierrados y no le ven sentido a tener que tirotearse por uno de los pibes que roban en el barrio. Pueden perder el respeto que les guarda el resto; se exponen. Es gente que roba mucha plata y sería una paradoja que caigan presos por tirotearse con uno de estos ladroncitos" (Idem).

Lo que se omite a través de este encadenamiento de lugares comunes que pone en circulación el discurso informativo (los jóvenes delincuentes son cada vez más peligrosos; roban y matan porque saben que no van presos) son las transformaciones sociales estructurales y correlativamente del crimen organizado entre aquel tiempo pasado y el presente; las explicaciones del delito se fijan en la naturaleza intrínseca de los sujetos y en una maldad inherente a esta. La incapacidad de los padres para "controlar" a sus hijos y la ligazón de la acción vecinal con el rol que supuestamente debería cumplir el Estado, esto es, "hablar con los padres", reactivan las matrices discursivas propias del paradigma del Patronato y dejan a la sombra las concepciones sobre los niños y adolescentes como sujetos de derechos y la frecuente vulneración de los mismos.

\section{De víctimas y victimarios. El rol del Estado}

El caso de análisis muestra la particularidad de que tanto el joven fallecido como aquel que se identifica como sospechoso de cometer el homicidio comparten el mismo nombre de pila. Este queda reservado en las noticias para mencionar a la víctima y funciona como elemento referencial en la serialización, "el crimen de Brian". Los apelativos (Perret, 1970) (4) utilizados para designar al presunto victimario en las primeras crónicas del caso son los términos "asesino" y "menor":

Se llama igual que el adolescente al que mató el sábado en Flores. Vivía en la villa 1-11-14, pero gracias a Facebook se descubrió que su madre lo mandó a Chile. Allí lo ocultó su papá (Clarín, 30 de diciembre de 2016). 
Mientras se espera que el vuelo que trae a Brian, el asesino de Brian Aguinaco, toque pista en Aeroparque, fuentes policiales confirmaron que cayó el otro delincuente que el sábado a la tarde habría participado del robo y luego asesinato del adolescente que estaba junto a su abuelo en el barrio de Flores y fue alcanzado por uno de los disparos realizados por los motochorros que le habían querido robar a dos mujeres en el cruce de Rivera Indarte y Asamblea (Clarín, 30 de diciembre de 2016b).

El juicio evaluatorio de condena se desplaza a "chico acusado" o "sospechoso" conforme avanzan las resoluciones de la justicia, tal como señala el titular del día diez de enero:

\section{Liberaron al chico de 15 años acusado de matar a Brian y lo enviaron a Perú}

En el intradiscurso, "menor de edad" funciona como objeto discursivo que otorga verosimilitud al relato, que narra las vicisitudes que atraviesan las fuerzas de seguridad argentina y chilena junto a Interpol en el momento de la detención del joven:

La Federal le pidió entonces al fiscal del caso, Ignacio Mahiques, que lanzara un "alerta azul" para oficializar un pedido a Interpol para que rastreara al chico, mientras se juntaban pruebas para ordenar su detención. No podían usar la clásica "circular roja" de las detenciones internacionales porque es un menor de edad.Entre tanto, la ministra de Seguridad de la Nación, Patricia Bullrich, se comunicaba con el ministro del Interior de Chile y le pedía colaboración. Mientras se cumplían las formalidades, Interpol ubicó al adolescente y a su padre en una casa, no muy lejos de la vivienda de unos tíos. Los puso bajo vigilancia y notificó a la Argentina. Finalmente, el juez Ricardo Farías ordenó la detención de Brian, pero por tratarse de un menor ésta no tenía carácter internacional (...) (Clarín, 30 de diciembre de 2016).

La enunciación se apoya en una "escena convalidada" (Maingueneau, 2003) que evoca el género policial cinematográfico reforzada por el uso de los conectores "mientras", "entre tanto" que produce el efecto de que los hechos suceden todos simultáneamente. La narración muestra eficiencia y legitimación del accionar del Estado y argumenta reiteradamente sobre la condición de "menor de edad" del joven detenido que se construye como un obstáculo para el accionar policial.

Desde otro lugar, la víctima del crimen es definida en las noticias mediante su nombre propio y sustantivos afectivos y adjetivos valorizadores, "nene" "adolescente" "joven":

Mediante la descripción de sus características personales, acciones y relaciones con sus allegados el relato sobre la vida de la víctima apunta a conmover:

Título: Un goleador que disfrutaba de las vacaciones con sus abuelos

Bajada: Brian Aguinaco tenía 14 años. Jugaba al fútbol en un club de barrio y era hincha de Boca. "Tata, llevame al hospital", alcanzó a decir cuando lo balearon. 
Se pueden identificar en algunos fragmentos enunciados que se relacionan con el pathos discursivo (Amossy, 2000), la apelación a los valores moviliza afectos y despierta sentimientos de piedad vinculados con la noción de injusticia.

Enrique y Brian eran inseparables. El vínculo entre ellos comenzó a construirse no bien su nieto nació, aquel 30 de octubre de 2002. (...)Fue ese abuelo, con el que compartió tantos momentos, el que estaba con él el sábado pasado al mediodía, cuando el balazo del motochorro le dio en el cuello y lo dejó en estado irreversible. Brian luchó por su vida hasta ayer cuando, ya internado en el hospital de Niños Ricardo Gutiérrez, fue desconectado del respirador artificial (Clarín, 26 de diciembre de 2016c).

La acentuación que se hace sobre la joven víctima con juicios axiológicos valorizadores y en contraposición la desvalorización y despersonalización del presunto victimario en la crónica policial alcanza a sus respectivas familias:

El chico es argentino pero tiene nacionalidad peruana. Sus padres son de Perú y, según fuentes del caso, están vinculados al narcotráfico de la villa 1-11-14. En un momento se temió que lo mandaran a esconderse a aquel país, algo que iba a dificultar aún más traerlo de regreso. Más allá de la condena de su padre, su madre está hoy bajo investigación en una causa de drogas. Tiene en su haber decenas de viajes a Perú, que ahora están bajo la lupa. Se habla de más de 40 (Clarín, 30 de diciembre de 2016).

La caracterización de los padres del "victimario" como vinculados al narcotráfico reiterada en numerosas noticias, a lo que se asocia el dato de la nacionalidad peruana en una cadena de equivalencia entre inmigración de países limítrofes y el accionar delictivo, funciona respaldando la hipótesis que señala la participación del joven en el crimen, al tiempo que argumenta sobre una suerte de "herencia delictiva". Por contraposición, los padres de la víctima representan los valores socialmente positivos asignados a lo familiar. Al ser interrogada sobre el proyecto del gobierno para bajar la edad de imputabilidad, la madre de Brian asigna a la función de los padres toda la carga de responsabilidad sobre el accionar de "los menores":

Los usan a los menores por eso, porque saben que entran y salen de las comisarías. Obviamente, los padres son los primeros responsables de cómo se criaron. Tal vez para ellos es normal, entonces también tienen que hacerse cargo los padres porque nosotros nos matamos para darle una educación y una buena vida a nuestro hijo. Entonces yo, como madre, no entiendo a esas madres que no crían bien a sus hijos, que no les dan una educación, que los dejan tirados. Por eso los chicos salen como salen. Pero no es justo que todos tengamos que pagar. A nosotros nos tocó ahora y mañana le va a tocar a otro. ¿Y cuántos casos anteriores hubo? Esto tiene que parar (Clarín, 8 de enero de 2017). 
La aceptabilidad de las proposiciones es reforzada por una máxima ideológica subyacente: todo padre debe y puede cuidar de sus hijos de la misma manera. El fragmento anterior se completa con la apelación al dolor: "(...) Porque nadie sabe el dolor. Nadie lo sabe. Uno se lo puede imaginar porque de hecho yo me podía imaginar el dolor de una madre. Pero nadie sabe lo que se siente. Que tomen conciencia un poquito". El dolor de una madre por la muerte de un hijo, que en nuestra cultura funciona como ideologema, aparece como argumento irrefutable en el pedido de justicia. En contrapartida, a la madre del joven sospechado le corresponden connotaciones criminalizantes y estigmatizadoras:

Un día después de la partida a Perú de Brian Joel, el chico de 15 años acusado por el crimen de Brian Aguinaco (14), Migraciones canceló la residencia permanente de su madre, Adriana González Cuadrado, una ciudadana peruana que tiene prisión preventiva en una causa por drogas y la habría violado para ayudar a escapar a su hijo. También le prohibieron el ingreso al país a su padre, condenado por narcotráfico, quien viajó a Lima con el menor (Clarín, 11 de enero de 2017).

Si los responsables morales de las conductas delictivas de los jóvenes son los padres, la responsabilidad social se atribuye a las leyes vigentes que "amparan" a los "jóvenes delincuentes". Esta premisa se enfatiza en la información producida el 10 de enero de 2017, luego de la liberación del joven detenido por el crimen y se postula a la baja en la edad de imputabilidad como una necesidad imperiosa tanto por parte de los familiares de la víctima como del propio gobierno que se muestra "impotente" frente a las resoluciones judiciales:

Título:"Impotencia total" en el Gobierno tras la liberación del acusado de matar a Brian

Bajada y cuerpo de la nota: La ministra de Seguridad, Patricia Bullrich, remarcó que movieron "cielo y tierra" para traer al chico de 15 años desde Chile.

El Gobierno tomó con una mezcla de resignación y bronca la medida de la Justicia que liberó al acusado de matar a Brian Aguinaco (14), aunque al mismo tiempo reconoce que la ley ampara al adolescente de 15 años porque no se lo puede imputar por su edad.(...) La funcionaria acotó: "Tenemos que votar el régimen penal juvenil urgente. Un joven de 15 años es consciente de lo que está bien y lo que está mal" (Clarín, 10 de enero de 2017b).

Título:"La ley hizo que esto pase", una queja unánime en la marcha por Brian

Bajada: La familia del chico de 14 años asesinado por motochorros se manifiesta tras la liberación del principal acusado del crimen (Clarín, 10 de enero de 2017).

La relación de correspondencia entre los pedidos de la familia de la víctima y el accionar de los funcionarios del gobierno nacional construye un mismo adversario para ambos: la ley -se sobreentiende- tal como está vigente, por lo tanto la baja en la edad aparece como una implicación lógica deóntica. 
Las acciones que se representan desde el Estado consisten en asistir a los padres de la víctima, recibirlos, dar explicaciones, dar respuestas sobre el caso y prometer políticas de endurecimiento penal:

"Vamos a contarles a los padres de Brian cómo detuvimos a estos dos asesinos, porque la justicia sana, y vamos a pedir a todos, a los jueces, a las fuerzas de seguridad, que cada minuto trabajemos para mejorar porque es la vida de la gente", aseguró la ministra (Clarín, 30 de diciembre de 2016b).

El presidente Mauricio Macri les prometió a los padres de Brian Aguinaco que enviará al Congreso el proyecto para bajar la edad de imputabilidad. Así lo aseguró Eliana Passada, madre del chico de 14 años asesinado en Flores el último 24 de diciembre (Clarín, 22 de enero de 2017).

En sentido contrario, las acciones que se proyectan desde el Estado sobre aquellos que son indicados como agentes de los delitos tienen que ver exclusivamente con las que se realizan a través de la agencia policial y judicial: "trasladado al juzgado"; "alojado en la comisaría"; "fue liberado sin poder ser juzgado y enviado a Perú".

Para fines del mes de febrero, el caso Brian en la agenda policial del medio se desplaza desde los hechos policiales hacia los hechos políticos. Clarín titula "A pesar de un informe, el Gobierno insistirá con la baja de la edad de imputabilidad" (25 de febrero de 2017). La noticia comenta los resultados obtenidos en la mesa de discusión convocada para tratar el tema, y se afirma la decisión del gobierno, a pesar de la oposición de numerosos sectores sociales y políticos, de enviar un proyecto al Congreso para que se baje la edad de imputabilidad. No hay aquí referencias al caso de Brian, que ya se ha diluido por completo en la agenda del delito. La nota política ingresa en la crónica policial sin restricciones de género, la ruptura genérica condensa la transformación de un hecho policial en un acontecimiento político en la que el foco de peligrosidad concentrado en los jóvenes postula la baja de la edad de imputabilidad como una medida necesaria.

\section{A modo de cierre}

Teniendo en cuenta lo señalado, se advierte que en estas crónicas se construye la escenografía de una novela policial, con los recursos propios del género. El formato narrativo, los testimonios de los vecinos y el entorno familiar de las víctimas, las fuentes policiales, judiciales y de los actores políticos que entran en escena contribuyen a construir un ethos (Maingueneau, 2002) que oscila entre un periodista objetivo y neutral, por un lado; y un "justiciero" que se compadece de las víctimas, por el otro. En la estrategia de ceder la palabra a los vecinos y al entorno familiar de las víctimas como fuente de legitimidad absoluta y silenciar 
las propias provenientes de los "victimarios"; en la interpelación desde el dolor y la construcción de lugares comunes que configuran a los jóvenes como menores delincuentes y sus familias como "germen" del delito, se edifica un discurso moralizante que provee definiciones excluyentes de ciudadanía. La muerte de Brian se configura en un caso conmocionante que encarna las demandas de inflación penal y el aumento del control y del castigo para determinados jóvenes que, en la narración mediática, no consiguen constituirse en sujetos plenos de derechos ni asignarse el privilegio de llamarse víctimas.

\section{Notas}

(1) Los "reformistas" se limitaron a modificar los artículos referidos a la baja de edad de imputabilidad y los "innovadores" estuvieron orientados a instalar un régimen de responsabilidad penal juvenil, que velara por el cumplimiento de derechos y garantías y medidas socioeducativas antes que punitivas. En este período se constató que la agenda legislativa se alteraba a la par de la repercusión mediática de hechos delictivos graves cometidos por adolescentes (Guemureman, 2015).

(2) Weinreich (1975) señala a los tiempos verbales indefinido, imperfecto, pluscuamperfecto, pretérito anterior y condicional, como tiempos narrativos (destinados a provocar en el alocutorio reacciones inmediatas); a diferencia de otros como el tiempo presente, el pretérito perfecto y el futuro que son tiempos comentativos (como fragmento de acción, modifican la situación de los interlocutores y los compromete mutuamente).

(3) Kerbrat-Obrecchioni señala que verbos y adverbios apreciativos pueden funcionar como subjetivemas, elementos mediante los que el enunciador produce un juicio de valor sobre el enunciado.

(4) Perret define los apelativos como elementos del léxico, utilizados en el discurso para nombrar a una persona o conjunto de personas. Los apelativos permiten identificar un referente, efectuar una predicación sobre él y manifiestan relaciones sociales.

\section{Bibliografía}

Amossy, R. (2000). L'argumentation dans le discours. Discourse politique, littérature d'idées, fiction. París: Nathan.

Angenot, M. (1982). La parole plamphlétaire. Typologie des discours modernes. París: Payot.

Angenot, M. (2010). El discurso social. Los límites históricos de lo pensable y lo decible. Buenos Aires: Siglo Veintiuno.

Arnoux, E. (2006). Análisis del discurso. Modos de abordar materiales de archivo (cap. 3). Buenos Aires: Santiago Arcos.

Bajtín, M. (1979). Estética de la creación verbal. México: Siglo XXI.

Brescia, F. (2011). Sobre eufemismos y paradojas: la violencia como problema y solución al "peligro" de la minoridad. IV Seminario Internacional Políticas de la Memoria: 
Ampliación del campo de los Derechos Humanos. Memoria y Perspectivas, Buenos Aires.

Bruxelles, S. y De Chanay, H. (1998). Acerca de la teoría de los topoi: estado de la cuestión. Escritos, 17-18, Puebla, UAP.

Charaudeau, P. y Maingueneau, D. (Dirs.) (2005). Diccionario de análisis del discurso. Buenos Aires: Nueva Visión.

Contursi, M.; Brescia, F. y Costanzo, G. (2009). Menores en conflicto con la ley: análisis de legislación y debates parlamentarios en las dos primeras décadas del siglo XX. En Memorias del XXVII Congreso ALAS 2009. Buenos Aires: ALAS.

Contursi, M.; Brescia, F. y Costanzo, G. (2010).Formas de legitimación del control social: debates parlamentarios y construcción de subjetividades en torno a la baja de edad de imputabilidad. En Actas del IV Congreso Internacional de Letras: transformaciones culturales. Debates de la teoría, la crítica y la lingüística en el Bicentenario. Buenos Aires: Universidad de Buenos Aires, Facultad de Filosofía y Letras, Carrera de Letras.

Courtine, J. J. (1981). Análisis del discurso político (el discurso comunista dirigido a los cristianos). Langages 62, número monográfico.

Daroqui, A. y Guemureman, S. (1999). Los "menores" de hoy, de ayer y de siempre: un recorrido histórico desde una perspectiva crítica. Delito y Sociedad, 13, UNL Ediciones, Santa Fe.

Daroqui, A. y Guemureman, S. (2001). La niñez ajusticiada. Buenos. Aires: Puerto.

Ford, A. (1994). Navegaciones. Comunicación, cultura y crisis. Buenos Aires: Amorrortu.

Ford, A. (1999). La marca de la bestia. Identificación, desigualdades e infoentretenimiento en la sociedad contemporánea. Buenos Aires: Norma.

Gramsci, A. (1949). Observaciones sobre el folklore. En Cuadernos de la cárcel: literatura y vida nacional. México: Juan Pablos Editor.

Gramsci, A. (1984). Los intelectuales y la organización de la cultura. Buenos Aires: Nueva Visión.

Guemureman, S. (2015). Jóvenes y sistema penal: de las leyes que no fueron y de las leyes que pueden ser. El espejo de Brasil. Revista Voces en el Fénix, 6(51), pp. 80-89.

Hall, S. (1981). La cultura, los medios de comunicación y el «efecto ideológico». En Curran, G. et al. Sociedad y comunicación de masas. México: FCE.

Kerbrat-Orecchioni, C. (1981). La enunciación. De la subjetividad en el lenguaje. Buenos Aires:Edicial.

Maingueneau, D. y Cossutta, F. (1995). L'analyse des Discourseconstituans. Langages, 117, pp. 112-125.

Maingueneau, D. (2002). Problèmes d'ethos. Pratiques, 113/114, pp. 55-67. 
Maingueneau, D. (2003). ¿ «Situación de enunciación» o «situación de comunicación»? Discurso.org, 2(5).

Perret, D. (1970). Les appellatifs. Analyse lexicale et actes de parole. Langages, 17.

Tufró, M. (2017). Comunidades del miedo. Algunas observaciones sobre la construcción de los vecinos en la tematización de la "inseguridad" en Clarín. En Martini, S. y Pereyra, M. (Comps.) La noticia hoy. Tensiones entre la política, el mercado y la tecnología. Buenos Aires: Imago Mundi.

Voloshinov, V. (1929). El marxismo y la filosofía del lenguaje. Madrid: Alianza.

Weinreich, U. (1975). Estructura y función de los tiempos en el lenguaje. Madrid: Gredos.

Zapiola, M.C. (2008). La Ley de Patronato de 1919. Una reestructuración parcial de los vínculos entre Estado y 'minoridad. Jornada "Historia de la infancia en Argentina, 1880-1960. Enfoques, problemas y perspectivas", UNGS-UDESA.

\section{Artículos periodísticos}

Clarín (26 de diciembre de 2016). Intentó defender a una vecina de un robo, le dispararon y balearon a su nieto de 14 años. Recuperado de https://www.clarin.com/policiales/intento-defender-vecina-robo-dispararon-balearonnieto-14-anos_0_S1BCTRT4I.html

Clarín (26 de diciembre de 2016b). Incidentes en la comisaría de Flores tras el crimen de un adolescente. Recuperado de https://www.clarin.com/policiales/incidentes-comisariaflores-crimen-adolescente_0_rJVVVQyrx.html

Clarín (26 de diciembre de 2016c). Un goleador que disfrutaba de las vacaciones con sus abuelos. Recuperado de https://www.clarin.com/policiales/goleador-disfrutabavacaciones-abuelos_0_SkN3SXJSg.html

Clarín (30 de diciembre de 2016). Cayó el asesino de Brian: tiene 15 años y sus padres lo habían ayudado a escapar. Recuperado de https://www.clarin.com/policiales/cayoasesino-brian-15-anos-padres-ayudado-escapar_0_rkCb-X7re.html

Clarín (30 de diciembre de 2016b). Un nuevo detenido por el crimen de Brian, el chico asesinado en Flores. Recuperado dehttps://www.clarin.com/policiales/nuevo-detenidocrimen-brian-flores_0_ryQSg6mBe.html

Clarín (2 de enero de 2017). La banda que mató a Brian les roba hasta sus propios vecinos en la villa 1-11-14 Recuperado de https://www.clarin.com/policiales/banda-mato-brianroba-propios-vecinos-villa-11-14_0_S1gdEUure.html

Clarín (2 de enero de 2017). Los padres de Brian encabezaron una emotiva marcha del silencio Recuperado de https://www.clarin.com/policiales/padres-brian-encabezaron-emotivamarcha-silencio_0_HyMrA8OHg.html 
Clarín (5 de enero de 2017). El barrio que recuerda a Brian y se encierra por el miedo a los robos. Recuperado de https://www.clarin.com/policiales/barrio-recuerda-brian-encierramiedo-robos_0_H19AIG2Be.html

Clarín (8 de enero de 2017). Queremos que la muerte de Brian sirva para algo. Recuperado de https://www.clarin.com/policiales/queremos-muerte-brian-sirva_0_BkGMU8g8x.html

Clarín (10 de enero de 2017). "La ley hizo que esto pase", una queja unánime en la marcha por Brian. Recuperado de https://www.clarin.com/policiales/ley-hizo-pase-queja-unanimemarcha-brian_0_SkOgbx78e.html

Clarín (10 de enero de 2017b). "Impotencia total" en el Gobierno tras la liberación del acusado de matar a Brian. Recuperado de https://www.clarin.com/policiales/impotencia-totalgobierno-liberacion-acusado-matar-brian_0_BJyRuxm8x.html

Clarín (11 de enero de 2017). Quieren que la mamá del acusado por el crimen de Brian se vaya del país. Recuperado de https://www.clarin.com/policiales/quieren-mama-acusadocrimen-brian-vaya-pais_0_BkSJpX4II.html

Clarín (22 de enero de 2017). Macri admitió que será difícil aprobar la baja en la edad de imputabilidad. Recuperado de https://www.clarin.com/policiales/macri-admitio-dificilaprobar-baja-edad-imputabilidad_0_HkVKCuMPe.html

Clarín (25 de febrero de 2017). A pesar de un informe, el Gobierno insistirá con la baja de la edad de imputabilidad. Recuperado de https://www.clarin.com/policiales/ida-vueltadelgobierno-baja-edad-imputabilidad_0_Syls0QJcl.html 